\title{
THE "FALSE" DEBATE BETWEEN POSITIVISM AND VERSTEHEN IN THE ORIGINS OF SOCIOLOGY
}

\author{
FRANCISCO JAVIER ULLAN DE LA ROSA
}

\begin{abstract}
The article revisits the debate between the positivists and non-positivists currents in sociology in the late nineteenth and early twentieth century, concluding that it is actually a false debate, due to the fact that, beyond their differences, both shared some of the basic principles of the paradigm of modernity. From this historical analysis the article seeks to draw lessons for the social sciences in the present, at a time when these seem to have reached a certain synthesis between the modern and postmodern epistemologies. The article shows us that such a synthesis was already prefigured in the writing of classical theorists as it is, in fact, an ineluctable structural law of science itself if it wants to escape from the trap of skepticism and epistemological nihilism. The article also explores how, as a consequence of the pervasiveness of the modern paradigm, a common ethnocentric bias can be traced in all the fathers of sociology and wonders whether sociology today has actually got rid of this problem.
\end{abstract}

Key words: epistemology of the social sciences; positivism; Verstehen; hermeneutics; modernity; postmodernity.

\section{Introduction: the double epistemological "iron cage" in the social sciences}

Half a century after the assault launched by poststructuralist and postmodern epistemology on the hitherto orthodox scientific positivist paradigm (Harvey, 1989; Turner, 1990; Giddens, 1990, 1998; Rosenau, 1992; Touraine, 1992; Wehling, 1992; Ritzer, 1997) the confrontation has substantially subsided and it appears that we are finally approaching a stable synthesis between the two adversaries, a superior scientific and epistemological stadium in which the modern paradigm will have been improved and refined thanks to the postmodern critique, without, however, relinquishing its main ambitious goals. But this essay is not about revisiting the last 50 years of the history of the social sciences. Rather, it reflects a desire to return to the first decades of sociology and to use this retrospective analysis to extract useful lessons for sociology today that will remind and show readers that the debate between the nomothetic and the ideographic, between objectivity/ universality and subjectivity/ contextuality, is by no means new or the fruit of this weakening of the modern paradigm that occurred after the trauma of the two world wars, in a post-colonial planet, but a debate that goes back to the very beginning of sociology as a scientific discipline. We have not been as original in our postmodern epistemological disquisitions as some may still think, nor were, 
for that matter, the 1968 counterculture movements that permeate our world vision today. The truly great countercultural postmodern movement was, for the matter, late eighteenth and nineteenth century Romanticism (Bond, 2011), the first reaction to the Enlightenment.

\section{The epistemological debate between positivism and Verstehen}

In the period in which sociology was in status nascendi as a discipline, theorists aligned themselves in two opposite epistemological groups: the positivists (theorists like Marx, Engels, Durkheim, Spencer, Halbwachs and Small in the United States) and the nonpositivists (in which we should include almost the entire German school—Simmel, Tönnies, Sombart and Weber-and those in the United States influenced by pragmatism-Mead, Dewey and Thomas). Within the positivist group there was no less an important subdivision separating Marx's and Engels' historical materialism from Spencer's and Durkheim's functionalism. And to complicate things further, across the epistemological debate lay a political-ideological one which separated the socialist, anti-capitalist (Marx, Engels, Tönnies, Halbwachs or the early Sombart) from the liberal, pro-capitalist (Spencer, Simmel, Durkheim, Weber, American sociology). All the positions that would compete within the arena of twentieth century Sociology were already present at its inception.

\section{The nomothetic positivist epistemology}

Positivism advocated the application of the same scientific method to both natural and social phenomena (Giddens, 1974; Halfpenny, 1982; Wacquant, 1992). It was formulated specifically by and for the social sciences by Auguste Comte between 1830 and 1848 (Pickering, 1993) and further developed by Herbert Spencer between 1851 and 1896) (Carneiro \& Perrin, 2002). For these authors, all observable phenomena obey universal laws which are independent from the observed objects. All kinds of science must, therefore, aspire to be nomothetic, that is, to formulate universal laws by means of a single method that can be summarized in the following steps (an example is given as to how this could be applied to a social phenomenon):

1) Gathering of discreet empirical data.

2) Comparative analysis of the data in search for regularities: a, b and c (discreet elements) are all men (or social groups) showing a certain common characteristic $x$ and all have been observed to behave in manner $y$.

3) Elaboration of hypotheses using inductive logic: it is likely that all men showing feature $x$ always behave in manner $y$.

4) The hypothesis is subject to verification. In some cases, as for some natural sciences (although not all-let us consider, for example astronomy) this can be done in a laboratory, artificially reproducing the conditions of interaction among the objects studied. In the case of most social sciences this is not possible (although there may be cases in which it is, especially in psychology) and such verification can only be done again through the comparative observation of real concrete situations. The positivist approach assumes, however, that the effectiveness of the comparative method, when systematically applied, can be close to that of a laboratory test. 
5) Formulation of a universal law through deductive logic: at any time and place all men $\mathrm{x}$ behave in manner $y$.

The positivist approach always presumes the existence of an independent relation between the object of study and the researchers/observers. Because the predicates of science have to be universal, valid at any given time and place, the object of study must always show certain parameters and characteristics regardless of who looks at it. This, in sociology, means the separation between social processes and the subjects/individuals who play the social roles in the two following senses:

a) An epistemological separation between social processes and social actors: social phenomena and the laws by which they are governed are independent from the values and ideologies of those who observe them. Ideas can, at the most, lead to a misinterpretation of society (as in, for example, Marx's "false consciousness" of alienated workers who "believe" society works in a certain way when the facts prove otherwise) but they do not build the ultimate reality themselves. Positivism rejects cultural relativism: contingent interpretations of reality, which are valid only for a certain context, do not exist, at least not at the highest level of knowledge. The meaning or sense of an object or an action is always a property of the object itself, unchanged regardless of who observes or tries to explain it. There is only one truth and science's mission is to unravel it, even though we may humbly acknowledge that we are still far from fully achieving this goal. All societies and cultures can be explained, in the last instance, according to the same parameters (the objective parameters set by the biological, ecological, economic and psychological reality of the human being as a natural species).

In its programmatically purest version, it was felt positive science could not only explain present or past phenomena but make forecasts based on the universality of the laws that govern those phenomena. At the end of the nineteenth century the most important of those predictions took the form of Unilineal Evolutionism. The history of mankind, it was thought, is determined by a universal law that inexorably leads to increasing levels of social complexity. All positivist theorists agreed on that, disagreeing only on the mechanisms by which this process was supposed to work: for Spencer, these were the physical principles of thermodynamics and the biological law of "the survival of the fittest"-it was, in fact, him and not Darwin, who coined this expression (Richards, 1987; Francis, 2007); for Marx and Engels, they were the structural dialectic of the class struggles (Worsley, 2002); and for Durkheim, the isostatic laws of a self-regulating social system (Giddens, 1978; Perrin, 1995). They would also disagree on their predictions for the future stage of social evolution: in Spencer (1969 [1851]) natural selection would lead to a perfectly efficient and balanced social system guided by the laissez-faire principle and the invisible hand of the market (a translation into the social terrain of the natural selection of the species); Durkheim would pick up on this same idea, although from a less Darwinist perspective (Giddens, 1978; Jones, 1986): Marx and Engels predicted that the malfunction of the capitalist political economy would inevitably lead to its replacement by a communist one, independently of the kind of human intervention that would bring it down (Marx \& Engels, 1998 [1848]; Worsley, 2002).

b) An ontological separation between social processes and actors: If society is objectively explainable and even predictable it is because a disembodied form of life (Durkheim's superorganism, Marx's social formation) has emerged from the natural 
ontology of its components, no less real than them but consisting of an intangible immaterial structure, made of the organized relations among its parts. Societal systems are similar, in that regard, to the rest of the biological and non-biological systems, although the intelligent nature of the human species adds some very special elements, the psychological and cultural, that must be taken into account to explain the system's operation. Positivism does not deny these elements have a role in the system but, ultimately, reduces their logic to the logic of the superorganism: this reductionism is present in all positivist theorists, from patriarchs like Spencer (1862) or Morgan (1877), to their much more recent heirs like the Cultural Materialism of White (1943) or Harris (1968, 1971, 1974), the sociobiology of Wilson (1978) and Fisher's (1982) Neo-Darwinism.

This epistemological and ontological separation of subject and object may mistakenly lead one to suppose that the positivist theorists advocated a politically aseptic stand vis$\grave{a}$-vis society. Nothing could be farther from reality: From Comte to Durkheim, not to mention the better known cases of the fathers of Marxism, the purported objectivity of science was praised as the perfect tool to improve the efficacy and accuracy of particular social engineering projects, projects that were, in most cases, advocated by the sociologists themselves. Positive science was, in general terms, put to the service of the ideals of technical progress and the conquest of nature (and in many occasions also of other human beings) (Saul, 1992). Separating science from its application to society revealed, in any case, an impossible endeavor for the positivist sociologists. The most dramatic case is probably that of Marx and Engels, whose whole lives were spent in the inevitable tension between the scientific analysis of social structures (historical materialism is a scientific method that made a great contribution to the social sciences that is widely accepted and applied by many authors today, regardless of their political adscription) and political commitment to socialist internationalism (Worsley, 2002), a tension finally resolved through their systemic ontologism and their unilineal evolutionism. Both Marx and Engels were so convinced of the inevitable demise of capitalism due to its internal systemic laws, that they perceived their political activism simply as a sort of endorsement of this dynamic, actions aimed, at the most, at speeding up the unavoidable outcome. Many leftist movements today still hold the same view.

\section{The family of ideographic epistemologies}

They were born and thrived in Germany as partial heirs to the cultural movement of Romanticism (Shalin, 1986). But, this must not lead us into the mistake of seeing their stance as radically antimodern and antirationalistic. Their approach must, rather, be contemplated as an attempt to moderate naturalistic determinism by means of a humanism that reinstated the importance of an "anthropocentric" world produced by the human being from its own psychological motivations. The main epistemological conclusion to be drawn from that was that knowledge about this human world could not be obtained by applying the same methodologies developed for the analysis of non-human phenomena.

Dilthey would raise the need for a systematic epistemological separation of the natural and the human sciences, which he called, literally, "Sciences of the Spirit" (Geisteswissenschaften). At that time the term "spirit" in German academic parlance went 
beyond the usual religious meaning to encompass the whole dimension of the mind and, therefore, culture.

There comes a point where the relations among the facts of the world of human spirit show themselves to be incommensurate with the uniformities of natural processes in that the facts of the human world cannot be subordinated to those established by the mechanistic conception of nature. Only then do we witness, not the inherent limits of knowledge based on experience, but rather the boundary where knowledge of nature ends and an independent human science, shaped by its own central concerns, begins (Dilthey, 1989 [1883], p. 63).

The goal of Geisteswissenschaften should be to "understand" (Verstehen, in German) those phenomena driven by the "spirit"; to "interpret" them in relation to their context, a context which, while collective, is historic and contingent (De Mul, 2004). Some authors understand this position as antipositivist (Gyedimin, 1975; Tack, 2010) but none of the Verstehen sociologists, and certainly not Dilthey, ever recanted the positivist faith that universal laws would be found in nature. They simply put social phenomena beyond that quest. The reaction, in sum, came from a different dimension of the same modern paradigm, individualism — an element that positivism, in spite of all its claims to be a harbinger of modernity, had utterly shunned - and cannot be considered less modern than its adversary. It never renounced either a second fundamental axis of modernity, rationality, giving up in any way on the quest of a rational understanding of human phenomena.

Dilthey's was never a "simple historicism" as claimed by some (Waisman, 1959): he always defended the scientific character of the Geisteswissenschaften and their ultimate integration within science as a whole:

The sciences of man, society and history take the sciences of nature as their basis in two ways: first, insofar as psychological units themselves can be studied only with the help of biology; second, insofar as nature is the medium of their purposive activity, which is aimed mainly at the domination of nature (Dilthey, 1989 [1883], pp. 70-71).

Different from the Naturwissenschaften but science nonetheless, the process of "Verstehen", although imbued with the virtues of empathy towards the studied phenomena, has nothing to do with an intuitive, emotional, spontaneous or ad hoc grasp of the world, but demands, on the contrary, a well-established set of standardized, rational analytical tools of interpretative general techniques that can be subsequently applied to the study of any contingent cultural world created by the agency of human bodies and minds. The process of understanding, insofar as it is determined by common conditions and epistemological means, must everywhere have the same characteristics (Dilthey, 1996 [1910], p. 237).

His work was heir to a hermeneutic tradition, initially addressed at the interpretation of the Sacred Scriptures, introduced by the rationalism of the Enlightenment which for the first time addressed the Bible not as a manifestation of a revealed divine truth but as a set of historical texts whose real meaning could be discovered through certain techniques of intertextual comparison and historical analysis. In the first half of the nineteenth century, Scheilermacher's hermeneutics would generalize the method to any kind of text and form of human communication (Outhwaite, 2001). Dilthey would refine the hermeneutic heritage with some of the techniques of linguistic analysis developed by Husserl in Logical 
Investigations (1900-01). For Dilthey, as for Husserl, language contributes to "significative apprehension" (Dilthey, 2002 [1910], p. 60).

The sociology of Verstehen was also influenced by two contemporary philosophical schools: the Neo-Kantian current, in particular the Southwest school (Köhnke, 1991) and Husserl's Phenomenology (Luckmann, 1978), both German. As opposed to Dilthey these two currents can be considered fully antipositivistic. For these two schools the objects are inseparable from the meaning that each particular individual grants them. Although they do not deny the existence of ontological objects per se, they consider them inseparable and co-constituted by the specific meaning the individual and culture attach to them. Nature or society understood as disembodied systems that work for themselves are outside our possibilities of cognition. The only thing that can be known is the reality (whether physical or social) endowed with human sense (and, therefore, at least partially shaped by us). This premise implies the impossibility of achieving an objective explanation of reality, one that is universally valid in all cultural contexts and to all human beings, in open contrast to the claims of Positivism.

However, the Sociology of Verstehen represented by Weber, Simmel or Tönnies, treading on Dilthey's path, was never that radical. Its declared goal was simply to place limits on the materialistic and systemic determinism of the positivists in order to save individual agency. It did not renounce developing a general analysis of social processes, but simply warned us that they would be neither predictive explanations nor absolute universal laws. They would rather see phenomena in terms of more or less majoritarian trends, of a more or less closeness to an ideal representation, points in a continuum, or of more or less likely possible effects for a certain cause. The Verstehen advocated the existence of a human world of actions, values and symbols partially independent of the material substrate on which it developed, not mechanically determined by systemic laws but constituted by its own internal historical, contingent codes, changing from society to society, in each period of history. Agency and reflexivity are not, as posed by the positivists, merely dependent variables of the material substrate or the social system, passively shaped by it, but factors in a feedback relation to the social system that modify the system as well as being modified by it. On the contrary, they would say, ideas/culture have a life of their own, culture has the ability to modify matter, and the agency and creativity of individuals the power to transform the social system.

In order to study human phenomena, the German school proposed that the inductive method of the natural sciences should be replaced with two other types of methodologies:

1. On the first level they proposed a hermeneutic methodology. Social phenomena were to be approached as text. The goal would be to "translate", to "decode", the "social and cultural text" of a particular time or place, describing it and exposing its own internal dynamics in a language that is understandable to the reader. Nomothetic aspirations are put aside, with the social scientist content to reduce the apparent chaos of reality to a simplified, comprehensible ideographical representation.

2. On the second level, however, the sociologists of Verstehen somehow returned to positivism when they affirmed that sociology could and should establish explanatory models that are reasonably valid in some sort of sense: revealing, for instance, the existence of a predominant trend or the degree of "probability" of a given model being more or less close to reality itself. These trends, these models, built on the basis of the 
comparative method, were not to be understood as "laws" in the sense of the natural sciences, nor were they to be confused with social reality in itself, a reality that will never be fully grasped, predictable or determined by any external force or factor different from human agency. These models, endowed with a partial explanatory power, would be referred to as "the form" by Simmel to distinguish them from the "content" (the individual human actions) (Levine, 1971; Watier, 2003) and as "ideal types" by Weber, conceptual abstractions extracted from empirical data, crafted by the sociologist with heuristic purposes as tools enabling us to come closer to a knowledge which is by definition elusive (Hekman, 1983; Freund, 1998).

It is, in short, as if to say: if you have problems understanding how an engine works, simply try to make a drawing of it. If you have difficulty in understanding a complex reality, split it into smaller parts and stick tags to each one. Sketches and labels to capture the motley reality of the empirical world: those seem to have been, in sum, according the author's intentions ideal types such as capitalism or the types of authority in Weber (1978 [1924]) as well as the concepts of Gemeinschaft and Gesellschaft in Tönnies. Many authors have pointed out how subsequent readings of the classic German sociologists misunderstood their epistemological positions, in the sense of reifying those categories and turning them into a sort of imitation of natural positivistic universal laws. This was, for example, what happened to Tönnies' Gemeinschaft and Gesellschaft concepts, clumsily used by many subsequent sociologists as ontologically different and mutually exclusive categories (Adair-Toteff, 1996; Bond, 2011), rather than simply theoretical ideal reference points at the extremities of a complex continuum of empirical particular societal forms, none of them completely coinciding with any of the two abstract concepts. And yet, as we will try to sustain in the conclusions section, a revisiting of the texts, and those of Max Weber in particular, shows there is, after all, more than a grain of truth in that positivist reading of the sociology of Verstehen.

In America, some of the most illustrious representatives of the first generation of sociologists at the University of Chicago, George Herbert Mead, Charles Cooley and John Dewey, were converging towards very similar positions from slightly different points of departure. They applied William James's pragmatism to the study of social phenomena (Goodman, 1995), delving into the conception of social phenomena as emanations of an autonomous symbolic and psychological realm that always necessarily calls for some sort of contextual decoding. But, in contrast to the German Verstehen sociologists, their work led to a lowering of the level of autonomy of the individual vis-à-vis his cultural milieu, "The individual mind can only exist in relation to other minds in a world of shared meanings" (Mead in Miller, 1982, p. 5).

In other words: individual agency is always conditioned by collective agency. Mead's position would be developed in full from the 1930s onwards by his disciple Herbert Blumer under the name of "symbolic interactionism" (Blumer, 1969; Shalin, 1986; Farganis, 2008). The central idea was, again, that people act upon the world based on the meaning that the world has for them, and therefore, culture, ideas, can and do change reality. People interact with one another by interpreting or defining the actions of others and not merely by reacting to the objective behavior of those others. Chicago, a city heavily segregated into ethnic communities with their own values and lifestyles, would turn out to be, much more than 
the most homogenous Berlin of the German sociologists, the ideal laboratory for testing the theories of this cultural relativism. Better than in almost any other place in the Western world, empirical observations in the American metropolis seemed to easily sustain the claim that the identity and behavior of the group and the individual were largely built on and by the game of social interrelations themselves. In this case, interrelations among culturally diverse groups forced to interact with each other in a circumscribed urban space. Such an interaction had led to the creation of a complex set of mutual prejudices and stereotypes that were (re)constructing ethnic barriers and behavior. Particularly groundbreaking was the discovery that the positive or negative images that an external group or individual projects on another can end up being accepted by the targeted group or individual, unconsciously become part of their/his identity and subsequently modify their/his behavior. By midcentury Robert K. Merton (1948) would label this phenomenon a "self-fulfilling prophecy", but the basics of the concept had already been expounded by authors like Thomas and Thomas (1928) and Blumer in the first decades of the century. It was tantamount to denying the possibility of a completely autonomous individual agency. Since we are unconsciously shaped by our sociocultural milieu the implication seems to be quite unavoidable: we are not totally in control of what we are, what we think and, to a certain extent, of what we do. Although symbolic interactionists do not think in terms of a superorganism in the way functionalism does but just insist that social interaction comes simply as the sum of the countless number of individual human actions, the shadow of an independent structure infused with some sort of life of its own is constantly looming above it. This is tantamount to the reintroduction of positivism through the backdoor. Thus, this line of reasoning would lead phenomena-such as racism — to be seen in a light that was undoubtedly positivist, as something eventually outside the realm of people's will and morality: one doesn't choose to be a white supremacist, one is "grown", "shaped", by an external process, a certain cultural milieu as such, much in the same way that a rock is weathered by a geological process. The fact that racism might not necessarily be seen as playing a part in the functional logic of a systemic superorganism, as an overt positivist explanation would want, does not dispel the fact that there is still "something" out there, above the sum of individual actions which is shaping, whether for a particular purpose or only for purely contingent, historical reasons, the behavior of individuals.

Symbolic interactionism's flirting with this ambiguous form of relativism was not intended to exonerate people of the prevailing racist attitudes of their time but, on the contrary, as a way to combat the ethnic prejudice and social tensions of the American metropolis, unmasking the systemic logic hidden behind them. But, consciously or not, that came at the price of not renouncing a certain form of positivism. Conclusion: positivist and Verstehen sociology share the fundamental principles of the paradigm of modernity.

If we go beyond the sophisticated epistemological frills deployed by the authors, the positivism/Verstehen debate reveals itself to be quite sterile for two main reasons:

1) Because the accusations reciprocally hurled at each other from both sides are to a great extent the result of subsequent reductionist readings: for positivism is not an absolute determinism denying the role of human agency or culture and nor is Verstehen a radical relativism that denies the existence of some sort of structural dynamics driving society beyond individual behaviors. 
2) And, most importantly, because both positions converge in a common ideological ground that makes many of the epistemological differences superficial in the very least and even, ultimately, irrelevant. That shared ground is no other than the cultural paradigm of modernity which shapes and underpins the Zeigeist of the time, and among whose principles the epistemological and ethical rationalism and the ethnocentric unilineal evolutionism are worth singling out.

Let's start by examining the first argument in some detail. We have already pointed out how positivism is ultimately embedded into the non-positivist models of Verstehen. Verstehen may have been a more humble form of rationalism but it was, in any case, an attempt to rationally understand social processes, including the irrational dimension of them. And in so being, it ultimately cannot be properly seen as an ideographic position, since any rational logic always operates through principles of cause and effect. Therefore, a rational approach to a phenomenon, whatever its nature, is always, necessarily, an explanatory one. In order to explain phenomena, you need to process data with the help of models and somehow objectify these models, treating them, for operational purposes, "as if" they were real. In that sense, there is no escape from some kind of nomothetic processing of reality, except an absolute relativistic irrationalism.

Some of Simmel's exegetes (Watier, 2003) maintain that he understood his so called "form" as possessing, in fact, a real existence (a clearly positivist position), not to be confused in any way with the image of the form (the ideographic representation) built by the sociologist. This same "background" ontologism is also present in Weber, in a somewhat inconsistent way only explainable by the author's reluctance to confess his ultimate vision of social phenomena as obeying some kind of objective laws: In Economy and Society Weber defines sociology as "a science which attempts the interpretative understanding of social action (this is the Verstehen part), in order thereby to arrive at a causal explanation (we enter the positivist field) of its course and effects" (Weber in Runciman, 1991, p. 7).

The coexistence between an ideographic Verstehen and a nomothetic explanation is even more evident in the lines that follow:

The meaning to which we refer may be either (a) the meaning actually intended either by an individual agent on a particular historical occasion or by a number of agents on an approximate average in a given set of cases or (b) the meaning attributed to the agent or agents, as types, in a pure type constructed in the abstract (Weber in Runciman, 1991, p. 7).

Probably the clearest proof of this can be found in his theory of authority. Weber interweaves his three ideal types (traditional, charismatic, rational-legal) in a systemic logic that is beyond the agency of individuals and that is postulated as, independent of any specific cultural context, universal and teleological. This logic is especially deterministic in the case of charismatic authority, that Weber considers "intrinsically" unstable because it needs constant legitimation and is just "inexorably" bound to mutate sooner rather than later into one of the other two (Adair-Toteff, 2005).

Charisma is a phenomenon typical of prophetic movements or of expansive political movements in their early stages. But as soon as domination is well established, and above all, 
as soon as control over large masses of people exists, it gives way to the forces of everyday routine (Weber, 1978, p. 252)

The process of routinization is enunciated not as one possible outcome among others but as a law, and the forces causing this transformation are none other than those derived from nature

One of the decisive motives underlying all cases of the routinization of charisma is naturally the striving for security (Weber, 1978, p. 252).

\section{Or from the objective constrains of the social structure}

Another important motive, however, lies in the objective necessity of adapting the order and the staff organization to the normal, everyday needs and conditions of carrying on administration (Weber, 1978, p. 252).

The needs of mass administration makes [legal bureaucratic authority] today completely indispensable (Weber 1978, p. 122).

The idea of the ultimate inevitability of a systemic logic in certain social phenomena can also be tracked in Tönnies: when laying out his socialist political program inspired in the traditional, ascribed-status agrarian communities, Tönnies has to acknowledge that a full return to the communal forms of social organization of the past is structurally impossible in urban industrial mass societies and must, therefore, be adapted to fit the structural constrictions of the modern world (Tönnies, 1947 [1887]). At the very least, if not totally deterministic, the recognition that the logic of the system heavily conditions human agency is quite evident.

The same considerations, but in the opposite direction, should be noted with regard to Marx and Engels' historical materialism. As has been pointed out by many authors (Harris, 1968; Williams, 1973; Bloch, 1975) the vulgar image depicting it as an absolute material or economic determinism is absolutely false and probably stems from a misinterpretation of excerpts as the following from the Preface to the Contribution to the Critique of Political Economy

In the social production of their life, men enter into definite relations that are indispensable and independent of their will, relations of production which correspond to a definite stage of development of their material productive forces. The sum total of these relations of production constitutes the economic structure of society, the real foundation on which rises a legal and political superstructure and to which correspond definite forms of social consciousness. The mode of production of material life conditions the social, political, and intellectual life process in general. It is not the consciousness of men that determines their being, but, on the contrary, their social being that determines their consciousness (Marx 2010 [1859], p. 92).

But, as a matter of fact, what historical materialism really does is establish a hierarchy of causalities (in which the material constrictions, no doubt, occupy central place) within a systemic schema in which the ideas and the human actions, the superstructure, are also granted the capacity to modify the material base. Infrastructure and superstructure are thus intertwined in a feedback loop, and all that Marxism affirms is that the first one has a bigger weight in the relationship than the second. A metaphor of great heuristic power is to imagine the infrastructure as a soccer pitch. The properties of the pitch strongly affect 
the type of game that can be played within its limits and even negatively determine some of its characteristics (it would be impossible to play games like basketball or water polo on a soccer pitch) but in no way does the material nature of the pitch completely dictate the specific rules of the game (we can perfectly imagine a soccer version where there are 9 or 14 players in each team instead of 11; there could be a soccer game lacking the offside rule, with bigger or smaller goals, etc.) nor the development and outcome of each single match (the concrete moves of the players) nor the rituals, motivations and meanings that the actors (players, fans, coaches) attribute to the game. And, eventually, no matter how constrictive the material conditions may be, the collective action, consciously or unconsciously driven, has plenty of space for maneuvering, for changing the rules and even changing the nature of the material constrictions themselves (the swath of land where our soccer pitch lies could eventually be transformed through the combined action of technology and work, into a basketball court or swimming pool).

Marx and Engels didn't use such a clear and comprehensive metaphor but there is no doubt that their position was exactly the same

Men make their own history, but they do not make it just as they please; they do not make it under circumstances chosen by themselves, but under circumstances directly found (Marx (1954 [1869], p. 10).

And as Engels clearly stated when defending historical materialism against some of his contemporaries who accused him of material determinism:

The economic situation is the basis, but the various elements of the superstructure-political forms of the class struggle and its results, to wit: constitutions established by the victorious class after successful battle, etc, judicial forms and then even the reflexes of all these actual struggles in the brains of the participants, political, juristic, philosophical theories, religious views and their further development into systems of dogmas-also exercise their influence upon the course of the historical struggles and in many cases preponderate in determining their form (Engels to J. Bloch, September 21-22, 1890, in Marx-Engels, 1962, p. 488).

And on the eventual reshaping of our material soccer pitch, Marx in fact put it this way:

[Man]... opposes himself to Nature as one of her own forces, setting in motion arms and legs, head and hands, the natural forces of his body, in order to appropriate Nature's productions in a form adapted to his own wants. By thus acting on the external world and changing it, he at the same time changes his own nature. He develops his slumbering power and compels them to act in obedience to his sway (Marx 1986 [1867], in Elster, p. 76).

Just as final proof of how close both sociological sides really were in the end, it is worth including the following quote by Max Weber

The process of routinization of charisma is in very important respects identical with adaptation to the conditions of the economy, since this is the principal continually operating force in everyday life (Weber, p. 54).

which amounts to nothing other than acknowledgment of the Marxists' thesis about the role of infrastructure in historical processes. 
Differences between the two sides of the debate also turn out to be very thin when we look at the second argument: the theorists' adherence to the core principles of the modern paradigm. Among these, one very relevant to the social sciences stands out: their stance with regard to evolutionism. Both sides of the sociological divide are, once again, much closer than has sometimes been portrayed. According to those such as Andreski (1984), Weber, with his reluctance to establish universal laws in history, would have advocated a multilineal evolutionist scheme. A multilineal model is undoubtedly developed by Weber, but, as we will see, this cannot lead us to misread it as an attempt to defy the modern narrative of the inevitability of social complexity and progress advocated by positivism. On the other hand we have to deal with the fact that at least some of the so-called positivist theorists never really denied the multilineal evolutionary model.

The famous unilineal sequence slavery-feudalism-capitalism-socialism modes of production is again a terrible ideological and vulgar reduction of the Marx and Engels model (Harris, 1968; Bloch, 1975). For them, it was always clear that historical evolution worked in a multilineal, "branching" way, ramifying in a vast array of political economies. Evidence of it was abundant in that era of colonial expansion that had put the West in contact with peoples in very different stages of social and technological complexity. Both theorists would devote, in fact, great efforts to the analysis of one of those multilineal ramifications, the so-called "Asian mode of production", fascinated by the idea that a complex and powerful political economy such as China had "failed" to evolve to the industrial stage (Marx, 1857 [1989]; Bernstein, 1971; Bloch, 1975; Gouldner, 1980). But snatching theorists like Marx and Engels from the clutches of their vulgar and reductionists interpreters does not, unfortunately, exonerate them from the crime of unilinealism: The fact that they contemplated the Chinese case as a sort of enigma to be solved is already proof of their culpability.

The Verstehen sociologists, on the other hand, were no less guilty of the same crime. At the end of the day, most of the declared multilineal evolutionism on both sides of the epistemological debate was nothing but a very well elaborated fallacy. All the work of the first sociological schools is laden with a complacent ethnocentric unilinealism (Wolff, 1950) that stems from their faith in the modern paradigm of progress. Everyone, all of them children of the Enlightenment, embraced it enthusiastically.

This ethnocentric evolutionism had been elevated, in the decades straddling the turn of the century, to the rank of the basilar myth of the Western cultural identity. The narrative had been reinforced by imperialism and the spectacular achievements of the industrial and scientific revolutions. It depicted the West as the spearhead of a civilizing progress driven by the engine of rationalization, a progress that in turn explained and justified its world domination. Beyond all the intricacies of epistemological Scholasticism, all founding fathers of sociology (such as those of the rest of the sciences) were, consciously or unconsciously, fierce and fervent believers of this myth. The narrative was so deeply infused in their minds that it acted as a full-fledged habitus which would prevent them from understanding history as anything short of an inevitable transformation forward, towards ever more rational/ progressive forms of society whose direct manifestations were always higher degrees of scientific-technological and social complexity and a greater capacity to create artificial environments through a more effective transformation and exploitation of nature. Of course, 
they were all very sophisticated intellectuals and trained researchers. As such, they couldn't just dismiss empirical evidence and were forced to acknowledge the coexistence of very different societies around the world. But we must not mistake that acknowledgement for a neutral, objective point of view vis-à-vis sociocultural diversity. Theirs is not a truly scientific, empirical, multilineal scheme but simply a more sophisticated historical model that ultimately, reveals itself to be a unilineal one. Historical processes, it is acknowledged, don't operate in the manner of a mathematical linear function: rather progress is a spiral movement and does not happen in all places simultaneously, resulting in the sprouting and coexistence (but only for a time) of very different societies around the world (the branches of a multilineal tree that was only temporary). But this acknowledged multilineality turns out ultimately to be, whether explicitly (as is probably the case with evolutionist sociology and anthropology and with Marxism) or implicitly (as in the case of Verstehen sociologists such as Weber), only a temporary one, since the driving logic of the process would force the more "backward" branches to eventually merge (as happens in many tree species) with the most progressive/strong ones or die out.

That was, without a doubt, the vision of all the first sociologists, the one lying below their more or less elaborate epistemological constructions: A clearly ethnocentric vision, unmistakably reeking of manifest destiny. The progress of reason is seen, in the last resort, as history's operational drive. Since, in their eyes, urban-industrial Western societies appeared to have been most profoundly shaped by rational processes, all other social forms were seen as historical cul-de-sacs, temporal phases or living fossils doomed to disappear sooner or later. Behind unilineal evolutionism hid the face of imperialism and a Western ethnocentric narcissism that can be summarized as follows: only we have managed to achieve modernity, ergo, you will have to be like us eventually because it is the only way to achieve progress. What was the alternative? It had been very clearly designed by Spencer in his biologicist dogma of the "survival of the fittest" that Hofstadter (1955)—mistakenly attributing it to Darwin-would later call Social Darwinism. In Spencer, that unavoidable ultimate rational phase of progress would take the form of a perfect self-regulating market. On the opposite side of the political spectrum, Marxist multilinealism would carry its own unilinealist torch with its faith in the structurally programmed demise of capitalism and the inexorable advent of a socialist society as a more rational form of urban-industrial civilization (Marx \& Engels, 1998 [1848]; Worsley, 2002).

And what of Max Weber, the great sacred cow of the Sociology of Verstehen, who advocated the agency of individuals and contingent cultures in the construction of history? A careful reading of his work leads us to discover his ultimate acknowledgment of systemic compulsions and his belief in an internal structural unilineal logic leading to successive levels of rationalization. Such rationalization is considered by Weber in Wissenschaft als Beruf (Science as Vocation) (1918-1919) to be "fate": "The fate of our times is characterized by the rationalization and intellectualisation and, above all, by the "disenchantment of the world" (Weber, 1946, p. 155). The same word is used in Economy and Society

It is the fate of charisma, however, to recede with the development of permanent institutional structures (Weber, 1978, p. 1134). 
In his 1920 Gesammelte Aufsätze zur Religionsoziologie (Sociology of Religion) it would be phrased as an "immanent law":

The more the world of the modern capitalist economy follows its own immanent laws, the less accessible it is to any imaginable relationship with a religious ethic of brotherliness. The more rational and, thus, impersonal, capitalism becomes the more this is the case (Weber, 1946, p. 331).

A law that would lead him to consider the evolution of religion, from the shamanic and magical stage to monotheism and, ultimately, secularism, as inevitable (Allan, 2005) and affirm the increasing incompatibility between the evolution towards a rational-legal structure of authority and forms of organization based on religious solidarities (Ritzer, 1992). Could that rationality have possibly evolved independently in different societies? We hear Weber say in his Sociology of Religion (1920): "The origin of a rational and secular ethics [ ...] was developed in a social context that it was strange to Asian cultures" (Weber in Bendix, 1960, pp. 337-38). The text is extremely revealing of two things: Weber's ultimate structuralism (ideas do not come about randomly but are products of certain social structures) and its profound ethnocentrism (rationality and secularity, two necessary conditions, in his view, to achieve modern progress, are an exclusive product of the Western culture). And even within the West, Weber would establish an ethnocentric gradation of more or less rational societies: in linking Protestant ethics to the development of capitalism (and the latter with progress and rationalization) Weber was placing the Catholic countries on a lower step of the evolutionary ladder (Weber, 2002 [1904]; 1978 [1924]). Building the steps of this ladder with increasing degrees of rationality and making reason the foundation of ethics he, like the rest of his contemporaries, would turn the multilineal stages of the evolutionary process into a moral ranking of human societies.

Weber's misgivings about the enunciation of overarching universal laws in history and society probably prevented him from ever presenting a systematic outline of his unilineal and ethnocentrical evolutionary scheme. However, this scheme can be perfectly reconstructed by the mindful assembling of his own reflections, like the pieces of a puzzle scattered all throughout his writings.

Thus, historical change is driven by an objective and systemic logic that is external to the individuals:

Rationalization and rational organization revolutionize "from the outside" (Weber, 1978, p. 1117).

And

That process of rationalization and association whose growing penetration into all spheres of social action we shall have to trace as a most essential dynamic factor in development (Weber, 1978, p. 333).

Rationalization operates throughout all the social system, from religion, to politics to economics allowing us to classify societies along a gradient of rationality as well as to explain the historical transitions between more primitive, less rational stages and more modern, rational ones. The model was Morgan's well-known savagery-barbarism-civilization 
(Morgan, 1877), with the same concession to orientalism found in Marx and Engels plus the addenda of an idiosyncratic form of Northern European protestant liberal ethnocentrism that established a final hierarchical evolutionary division within the realm of Western modern culture itself between the northern European capitalist nations, the less industrialized catholic southern European countries and the eastern European agrarian and communist societies.

The initial stage is one "where economic conditions are undifferentiated" and "it is hardly possible to discern a special political community (Weber, 1978, p. 905), a stage in which, "basic functions [...] lack any form of rational order. They are performed, instead by amorphous ad hoc groups" (Weber, 1978, p. 905). In these "early stages of social life, every concerted action that transcends the traditional mod of satisfying economic needs in the household has a charismatic structure" (Weber, 1978, p. 1133). Then, as rationalization advances as "points in the evolutionary sequence" (Weber, 1978, p. 607) "it is the fate of charisma to recede before the powers of tradition or of rational association" (Weber, 1978, p. 1148). The next stage is the "stereotyped feudal-patrimonial administration" (Weber, 1978, p. 1086). Here Weber classifies the Western medieval society and the modern and present Asian societies, neither of which shows

[...] the superiority of bureaucratic administration [...] technical knowledge [and] the development of modern technology and business methods in the production of goods [...] it makes no difference whether the economic system is organized on a capitalistic or a socialistic basis (Weber, 1978, p. 223).

Rationality is always the yardstick to measure past periods of European history or NonWestern societies. "Feudal conduct leads to the opposite of the rational economic ethos and is the source of that non chalance in business affairs" (Weber, 1978, p. 1106).

Then comes the rise of the State, in the form of a progressive "preeminence of the legal order guaranteed by the political power" that "has arisen only in the course of a very gradual development" (Weber, 1978, p. 904). And finally, "the progress toward the bureaucratic state, adjudicating and administering according to rationally established law and regulation is nowadays very closely related to the modern capitalist development" (Weber, 1978, p. 394), the last stage of evolution. "The so-called progress toward capitalism has been the unequivocal criterion for the modernization of the economy since medieval times" (Weber, 1978, p. 393).

In the religious realm, Western systems of belief are considered as more rational that Eastern ones, and coadjuvant factors in the evolution towards ever more progressive stages of socioeconomic organization in a moral hierarchical sequence that places Catholicism in a less rational stage $v i s-\grave{a}$-vis Protestantism.

We desire only to establish the existence of an affinity between economic rationalism and certain types of rigoristic ethical religion [...] This affinity comes to light only occasionally outside the Occident, which is the distinctive seat of economic rationalism (Weber, 1978, p. 480).

No path led from the magical religiosity of the non-intellectual strata of Asia to a rational, methodical control of life (Weber, 1978, p. 201). 
The more favorable constellation for capitalist development that Occidental Catholicism offered (in comparison with these Oriental religions) was primarily due to the rationalization of hierocratic domination undertaken in continuation of ancient Roman traditions. This refers especially to the manner in which science and jurisprudence were developed. The Oriental religions preserved the unrationalized charismatic character of religiosity more than did the Occidental churches (Weber, 1978, p. 92).

Only in the Occident, where the monks became the disciplined army of a rational bureaucracy of office, did other-wordly asceticism become increasingly systematized into a methodology of active, rational conduct of life. Moreover, only in the Occident was the additional step takenby ascetic Protestantism- of transferring rational asceticism into the life of the world (Weber, 1978, p. 555).

Catholicism was still too hindered by irrational quasi polytheistic (Weber, 1978, p. 518) and magical practices (Weber, 1978, p. 421) to be the vehicle of the final evolutionary leap toward rationalization.

Only ascetic Protestantism completely eliminated magic and the supernatural quest for salvation [...] It alone created the religious motivations for seeking salvation primarily through immersion in one's worldly vocation [...] For the various popular religions of Asia, in contrast to ascetic Protestantism, the world remained a great enchanted garden, in which the practical way to orient oneself, or to find security in this world or the next, was to revere or coerce the spirits and seek salvation through ritualistic, idolatrous, or sacramental procedures (Weber, 1978, p. 630).

Weber's shortsighted ethnocentrism prevented him from seeing the same capitalistic ethos in Confucianism, as is widely acknowledged nowadays (Lew, Woo-Young Choi, \& Hye Suk Wang, 2011).

As opposed to what was the general zeitgeist of the time, at no time did Weber, nor the rest the other fathers of Sociology for that matter, adopt an explicitly racist stance. They never denied the possibility of rational progress to Non-Western societies. For Weber, the cause lay in culture, not in biology. But, of course, this does not change one iota of the nonchalant Western, white, Protestant male moral complacency that exudes from his pages. But has sociology, after several decades of postmodern revolution, really caused itself to become "disenchanted" with at least the most ideological facets of the paradigm of modernity? Or are we still stuck with it, in spite all our explicit criticism, just as the positivist and Verstehen schools were in their time? Isn't it the case that we, sociologists and general public alike, still see, to a certain extent, our urban-industrial technological culture as an inevitable, and desirable, destiny of human kind? And much more so, in the light of globalization, than in the imperialist era of one century ago? Isn't it that we still expect from science nothing else than an objective and effective account to understand the world and transform it for our sake?

All these lessons basically boil down to the following conclusion: The debate between supporters of the discovery of universal laws and objective structures (positivists) and the supporters of interpretative models with only contextual validity (synthesized here in the term of Verstehen, interpretation, in German) was then, and it is now, an epistemologically void one. And this is so because the basic parameters of the epistemology and ethics of modernity are present in the work of all theorists of yesterday as they are in many of today. We are just left to wonder if it could be otherwise. 
Sociology today, in spite of all its postmodern rhetoric, is still stuck in the same epistemological conundrum. Attacks on Positivism have always led, then as now, to a limited set of amendments, to projects for the partial reform of the paradigm, but never a replacement with something radically different.

The comparison between the debate initiated by the parents of sociology and the one that set ablaze the social sciences in the last few decades reveals the existence of an inescapable double "iron cage" from which we will never break out: On the one hand there can be no pretense of science or knowledge without pretension of some kind of truth (even when this truth states that the "truth" is subjective and contextual) and, therefore, of some sort of objectification and universality; and this is the case even when facing the study of human society and culture and its inherently self-referential processes. The only alternative to that would be a total epistemological nihilism, something not a single reasonable theorist has ever sustained. On the other hand, even if someone seeks knowledge for its own sake, devoid of intent of use, that someone could only prevent it from being used by others by hiding it. The fact is that knowledge, the "truth", once it goes public, is bound to be applied to some kind of social practice and, therefore, is inexorably linked to one or many possible agendas which are subjective and contextual to social ideologies, to the models of society that we want to maintain or to build and that will tend to be ethnocentric. We all like to consider ourselves to live in the best possible of societies. This is true of the West and western versions of sociocultural evolutionism as it is true for other idiosyncratic forms of past and present sociocultural evolutionism, from the communist one developed in the former USSR (and still present, with local nuances in North Korea, Cuba or Venezuela) to that concocted by the Iranian Islamic Revolution or present Islamic Sunni jihadism.

\section{References}

Adair-Toteff, C. (1996). Ferdinand Toennies: Utopian visionary. Sociological Theory, 13, 58-65.

Adair-Toteff, C. (2005). Max Weber's charisma. Journal of Classical Sociology, 5(2), 189-204.

Allan, K. D. (2005). Explorations in classical sociological theory: Seeing the social world. London: Pine Forge Press.

Andreski, S. (1984). Max Weber's insights and errors. London: Routledge.

Bendix, R. (1960). Max Weber: An intellectual portrait. Abingdon: Taylor \& Francis.

Bernstein, R. J. (1971). Praxis and action: Contemporary philosophies of human activity. Philadelphia: University of Pennsylvania Press.

Bloch, M. (1975). Marxist analyses and social anthropology. London: Malaby Press.

Blumer, H. (1969). Symbolic interactionism: Perspective and method. New York: Prentice Hall.h

Bond, N. (2011). Ferdinand Tönnies's romanticism. The European Legacy, 16(4) , 487-504.

Carneiro, R. L., \& Perrin, R. G. (2002). Herbert Spencer's principles of sociology: To centennial retrospective and appraisal. Annals of Science, 59(3), 221-261.

De Mul, J. (2004). The tragedy of finitude: Dilthey's hermeneutics of life. New Haven, CT: Yale University Press.

Dilthey, W. (1989 [1883]). Selected works. Vol. 1. Introduction to the human sciences. Princeton: Princeton University Press.

Dilthey, W. (1996 [1910]). Selected Works. Vol. 4. Hermeneutics and the study of history. Princeton: Princeton University Press. 
Dilthey, W. (2002 [1910]). Selected Works. Vol. 3. The formation of the historical world in the human sciences. Princeton: Princeton University Press.

Farganis, J. (2008). Readings in social theory. New York: McGraw Hill.

Fisher, H. (1982). The sex contract: The evolution of human behavior. New York: W. Morrow.

Francis, M. (2007). Herbert Spencer and the invention of modern life. Newcastle (UK): Acumen Publishing.

Freund, J. (1998). The sociology of Max Weber. London: Routledge.

Giddens, A. (1974). Positivism and sociology. Portsmouth (New Hampshire): Heinemann.

Giddens, A. (1978). Durkheim. London: Fontana Modern Masters.

Giddens, A. (1990). The consequences of modernity. Palo Alto: Stanford University Press.

Giedymin, J. (1975). Antipositivism in contemporary philosophy of social science and humanities. The British Journal for the Philosophy of Science, 26, (4), 275-301.

Goodman, R. B. (1995). Pragmatism: A contemporary reader London: Routledge.

Gouldner, A. W. (1980). The two Marxisms. Oxford: Oxford University Press.

Halfpenny, P. (1982). Positivism and sociology: Explaining social science London: Allen \& Unwin.

Harris, M. (1968). The rise of anthropological theory. New York: Harper \& Row.

Harris, M. (1971). Culture, man, and nature: An introduction to general anthropology. New York: Crowel.

Harris, M. (1974). Cows, pigs, wars, \& witches: The riddles of culture. New York: Random HouseVintage.

Harvey, D. (1989). The condition of postmodernity. Oxford: Blackwell.

Hekman, S. (1983). Weber, the ideal type, and contemporary social theory. Notre Dame, Ind.: University of Notre Dame Press.

Hofstadter, R. (1955). Social Darwinism in American thought. Boston: Beacon Press.

Jones, R. A. (1986). Emile Durkheim: An introduction to four major works (Vol. 2). Beverly Hills, CA: Sage Publications.

Köhnke, K. C. (1991). The rise of Neo-Kantianism: German academic philosophy between idealism and positivism. Cambridge (UK): Cambridge University Press.

Levine, D. (Ed.) (1971). Simmel: On individuality and social forms, Chicago: Chicago University Press.

Lew, Seok-Choon, Woo-Young Choi, \& Hye Suk Wang. (2011). Confucian ethics and the spirit of capitalism in Korea: The significance of filial piety. Journal of East Asian Studies, 11(2), 171-196.

Luckmann, T. (1978). Phenomenology and sociology: Selected reading. New York: Penguin Books.

Marx, K. (2010 [1859]). A contribution to the critique of political economy (pp. 98-130). New York, NY: Palgrave Macmillan.

Marx, K. (1954 [1869]), The eighteenth Brumaire of Louis Bonaparte, Moscow: Progress Publishers.

Marx, K., \& Elster, J. (1986). Karl Marx: A reader. Cambridge: Cambridge University Press.

Marx, K., \& Engels, F. (1962). Selected works Vol II. Moscow: Foreign Languages Publishing House.

Marx, K., \& Engels, F. (1998 [ 1848] ). Communist manifesto. Barcelona: Critical.

Marx, K. (1989 [1857]). Key elements to the critique of political economy: "Grundrisse" 1857-1858. Twenty-first century, Mexico D. F.

Miller, D. L. (Ed.) (1982). The individual and the social self: Unpublished essays by G. H. Mead. Chicago: University of Chicago Press.

Morgan, L. H. (1877). Ancient society; or, researches in the lines of human progress from savagery, through barbarism to civilization. New York: H. Holt.

Merton, R. K. (1948). The self-fulfilling prophecy. The Antioch Review, 8(2), 193-210.

Outhwaite, W. (2001). History of hermeneutics. International Encyclopaedia of the social and behavioral sciences (Vol. 10), pp. 6661-5. Amsterdam: Elsevier. 
Perrin, R. G. (1995). Emile Durkheim's “Division of Labor” and the shadow of Herbert Spencer. The Sociological Quarterly, 36(4), 791-808.

Pickering, M. (1993). Auguste Comte: An intellectual biography. Cambridge (UK): Cambridge University Press.

Richards, R. J. (1987). Darwin and the emergence of evolutionary theories of mind and behavior. Chicago: University of Chicago Press.

Ritzer, G. (1992). Sociological theory. New York: McGraw-Hill.

Ritzer, G. (1997). Postmodern social theory New York: McGraw-Hill.

Rosenau, P. M. (1992). Post-modernism and the social sciences: Insights, inroads, and intrusions. Princeton, New Jersey: Princeton University Press.

Runciman, W. G. (1991). Weber. Selections in translation. Cambridge (UK): Cambridge University Press.

Saul, J. R. (1992). Voltaire's bastards: The dictatorship of reason in the West. Glencoe, Illinois: Free Press.

Shalin, D. N. (1986). Pragmatism and social interactionism. American Sociological Review, 51(1) (February), 9-29.

Shalin, D.N. (1986). Romanticism and the rise of social hermeneutics. Social Research, 53, (1), 77-123.

Spencer, H. (1969 [1851]). Social statics. New York: Robert Schalkenbach Foundation.

Spencer, H. (1862). First principles of a new system of philosophy. London: Williams and Norgate.

Tack, J. (2010). Causality in qualitative and quantitative research. Quality and Quantity, 45, (2), 263-291.

Thomas, W. I., \& Thomas, D. S. (1928). The child in America. New York: A. A. Knopf.

Tönnies, F. (1947 [1887]). Community and society. Buenos Aires: Losada publishers.

Touraine, A. (1992). Critique de la modernité. Paris: Fayard.

Turner, B. S. (Ed.). (1990). Theories of modernity and postmodernity. London: Sage.

Wacquant, L. (1992A). Positivism. In T. Bottomore \& W. Outhwaite. (Eds.), The Blackwell dictionary of twentieth-century social thought. London: Blackwell.

Waismann, A. (1959). Dilthey or lyricism of historicism. Universidad Nacional de Tucumán, Faculty of Philosophy and Letters.

Watier, P. (2003). Simmel sociologue. Paris: Circe.

Weber, M. (2002) [1904].The Protestant ethic and the spirit of capitalism: and other writings. London: Penguin.

Weber, M. (1946). From Max Weber: Essays in sociology. In H. H.Gerth, \& C.Wright Mills (Eds.). Oxford: Oxford University Press.

Weber, M. (1978) [1924]. Economy and society. Los Angeles: University of California Press.

Wehling, P. (1992). Als die Moderne Sozialmythos: Zur Kritik sozialwissenschaftlicher Modernisierungstheorien. Frankfurt am Main: Campus.

White, L. (1943). Energy and the evolution of culture. American Anthropologist, 45, (3), 333-356 .

Wilson, E. O. (1978). What is sociobiology. Society, 15(6), 10-14.

Williams, R. (1973). Basis and superstructure in Marxist cultural theory. New Left Review, 1(82), 5-16.

Wolff, K. H. (Ed.). (1950). The sociology of Georg Simmel. New York: The Free Press.

Worsley, P. (2002). Marx and Marxism. London: Routledge.

Sociology II Department,

University of Alicante,

Conrado Albaladejo 39, bw 30

Alicante 03540

Spain

Email: javierullan@hotmail.com 